\title{
هִ The medial wall of the cavernous sinus. Part 2: Selective medial wall resection in 50 pituitary adenoma patients
}

\author{
Salomon Cohen-Cohen, MD, ${ }^{1,3}$ Paul A. Gardner, MD, ${ }^{1}$ Joao T. Alves-Belo, MD, ${ }^{1}$ Huy Q. Truong, MD, ${ }^{1}$ \\ Carl H. Snyderman, MD, MBA, ${ }^{2}$ Eric W. Wang, MD, ${ }^{2}$ and Juan C. Fernandez-Miranda, MD ${ }^{1}$ \\ Departments of ${ }^{1}$ Neurological Surgery and ${ }^{2}$ Otolaryngology, University of Pittsburgh School of Medicine, Pittsburgh, \\ Pennsylvania; and ${ }^{3}$ Department of Neurological Surgery, National Institute of Neurology and Neurosurgery, Mexico City, Mexico
}

\begin{abstract}
OBJECTIVE Pituitary adenomas often invade the medial wall of the cavernous sinus (CS), but this structure is generally not surgically removed because of the risk of vascular and cranial nerve injury. The purpose of this study was to report the surgical outcomes in a large series of cases of invasive pituitary adenoma in which the medial wall of the CS was selectively removed following an anatomically based, stepwise surgical technique.

METHODS The authors' institutional database was reviewed to identify cases of pituitary adenoma with isolated invasion of the medial wall, based on an intraoperative evaluation, in which patients underwent an endoscopic endonasal approach with selective resection of the medial wall of the CS. Cases with CS invasion beyond the medial wall were excluded. Patient complications, resection, and remission rates were assessed.
\end{abstract}

RESULTS Fifty patients were eligible for this study, 15 (30\%) with nonfunctional adenomas and 35 (70\%) with functional adenomas, including 16 growth hormone-, 10 prolactin-, and 9 adrenocorticotropic hormone (ACTH)-secreting tumors. The average tumor size was $2.3 \mathrm{~cm}$ for nonfunctional and $1.3 \mathrm{~cm}$ for functional adenomas. Radiographically, 11 cases (22\%) were Knosp grade 1, 23 (46\%) Knosp grade 2, and 16 (32\%) Knosp grade 3. Complete tumor resection, based on intraoperative impression and postoperative MRI, was achieved in all cases. The mean follow-up was 30 months (range 4-64 months) for patients with functional adenomas and 16 months (range 4-30 months) for those with nonfunctional adenomas. At last follow-up, complete biochemical remission (using current criteria) without adjuvant treatment was seen in 34 cases $(97 \%)$ of functional adenoma. No imaging recurrences were seen in patients who had nonfunctional adenomas. A total of 57 medial walls were removed in 50 patients. Medial wall invasion was histologically confirmed in $93 \%$ of nonfunctional adenomas and $83 \%$ of functional adenomas. There were no deaths or internal carotid artery injuries, and the average blood loss was $378 \mathrm{ml}$. Four patients (8\%) developed a new, transient cranial nerve palsy, and 2 of these patients required reoperation for blood clot evacuation and fat graft removal. There were no permanent cranial nerve palsies.

CONCLUSIONS The medial wall of the CS can be removed safely and effectively, with minimal morbidity and excellent resection and remission rates. Further follow-up is needed to determine the long-term results of this anatomically based technique, which should only be performed by very experienced endonasal skull base teams.

https://thejns.org/doi/abs/10.3171/2018.5.JNS18595

KEYWORDS medial wall of cavernous sinus; invasive adenoma; parasellar ligament; endoscopic endonasal transcavernous; pituitary surgery

$\mathrm{P}$ ITUITARY adenomas with cavernous sinus (CS) invasion are associated with an increased risk for incomplete resection and recurrence. $1,7,8,14,16,19,22,23$ Often, they invade the medial wall of the CS without extending into the CS compartments. ${ }^{3,12,16,28}$ Different surgical techniques to maximize the degree of resection for invasive adenomas have been previously reported..$^{2,9,12,16,17,27}$ Surgi- cal removal of the medial wall of the CS, while potentially important to increase remission rates and decrease tumor recurrence, is generally not performed due to the risk of vascular and cranial nerve injury and significant blood loss. ${ }^{14}$

Our recent anatomical investigations, described in part 1 of this study, ${ }^{25}$ have shown that the medial wall of the

ABBREVIATIONS ACTH = adrenocorticotropic hormone; $\mathrm{CN}=$ cranial nerve; $\mathrm{CS}=$ cavernous sinus; $\mathrm{EEA}=$ endoscopic endonasal approach; $\mathrm{GH}=$ growth hormone; ICA = internal carotid artery; IGF-I = insulin-like growth factor-1; IHA = inferior hypophyseal artery; UFC = urinary free cortisol.

SUBMITTED March 5, 2018. ACCEPTED May 2, 2018.

INCLUDE WHEN CITING Published online September 7, 2018; DOI: 10.3171/2018.5.JNS18595. 
$\mathrm{CS}$ is formed by a single layer of meningeal dura that surrounds and attaches to the pituitary gland. It has multiple ligaments that support its adherence to the internal carotid artery (ICA) and the other walls of the CS., ${ }^{4,5}$ The surgical technique described in part 1 for selective removal of the medial wall of the CS is based on an accurate understanding of the dural layers, CS ligaments, and cavernous ICA trajectory and branches.

The purpose of this study was to report the surgical outcomes in a large series of patients with invasive pituitary adenomas who underwent an endoscopic endonasal approach (EEA) for selective removal of the medial wall of the CS performed according to our anatomically based stepwise surgical technique, which is described in part $1 .^{25}$

\section{Methods}

\section{Patient Population and Inclusion/Exclusion Criteria}

The University of Pittsburgh Medical Center database of clinical and radiological outcomes was reviewed to identify patients who underwent an EEA for invasive pituitary adenoma with selective resection of the medial wall of the CS since implementation of that technique in April 2012. Imaging studies, medical files, operative reports, and pathology results were analyzed. Inclusion criteria were: 1) functional or nonfunctional pituitary adenoma with isolated medial wall invasion based on intraoperative assessment; and 2) selective resection of the medial wall. We excluded all patients with destruction of the medial wall and invasion of the CS beyond the medial wall. Data were collected using Microsoft Excel 2016 (Microsoft Corp.), and statistical analysis was performed using SPSS version 24 (IBM Corp.).

\section{Endocrinology Evaluations and Remission Criteria}

All patients had a baseline preoperative hormonal evaluation, and the work-up for functional adenomas was performed in collaboration with the endocrinology team at our Pituitary Center. Remission was determined using modern criteria: insulin-like growth factor-I (IGF-I) level in the age-adjusted normal range and a $\mathrm{GH}$ level less than $1.0 \mu \mathrm{g} / \mathrm{L}$ from a random growth hormone (GH) measurement for patients with $\mathrm{GH}$-secreting tumors; ${ }^{6}$ morning serum cortisol $\leq 5 \mu \mathrm{g} / \mathrm{dl}$ or urinary free cortisol (UFC) $<10-20 \mu \mathrm{g} / \mathrm{dl}$ within 7 days of selective tumor resection for patients with Cushing's disease. ${ }^{15}$ UFC levels and/or salivary cortisol were evaluated subsequently every 3 to 6 months postoperatively for 2 years and annually thereafter to rule out recurrence. Patients with prolactin-secreting tumors were considered in remission if their plasma prolactin level returned to normal without visible radiological tumor remnants and without requiring dopamine agonist therapy. The indications for surgical intervention in these patients with prolactinomas included medication intolerance, resistant tumors, and patient preference.

\section{Imaging Studies and Follow-Up}

The radiological evaluation consisted of MRI with and without contrast, performed preoperatively and at 3- to 6 -month intervals during the 1st year and yearly there- after. Tumor sizes were recorded as microadenomas $(<1$ $\mathrm{cm})$ and macroadenomas $(\geq 1 \mathrm{~cm})$ based on the greatest diameter on a coronal image. Tumors were also categorized according to the Knosp classification.

\section{Results}

\section{Tumor and Patient Demographics}

From a database of 410 pituitary adenomas operated on during the study period, a total of 50 cases were selected based on the inclusion criteria. The patients' mean age at surgery was 49 years, and the female/male ratio was 1:1. Primary surgery was performed in 45 cases $(90 \%)$ and reoperation in 5 cases (10\%). All patients underwent a single operation. A summary of patient and tumor characteristics is shown in Table 1.

In every case, the diagnosis was histologically confirmed; diagnoses included functional adenomas $(\mathrm{n}=35$, $70 \%)$ and nonfunctional adenomas $(\mathrm{n}=15,30 \%)$. There were 17 microadenomas (34\%) and 33 macroadenomas (64\%). The mean maximum tumor diameter was $15.9 \mathrm{~mm}$ (range 5-38 mm, median $15 \mathrm{~mm}$ ). Radiologically, 11 cases (22\%) were Knosp grade 1, 23 (46\%) Knosp grade 2, and $16(32 \%)$ Knosp grade 3. GH-secreting adenomas were the most common functional tumors $(46 \%)$, followed by prolactin-secreting adenomas (28\%) and adrenocorticotropic hormone (ACTH)-secreting adenomas (26\%). Illustrative cases of a GH-secreting adenoma and a nonfunctional adenoma are shown in Video 1 and Video 2, respectively.

VIDEO 1. Endoscopic endonasal approach for a GH-secreting pituitary adenoma and selective resection of the medial wall of the CS. Copyright Salomon Cohen-Cohen. Published with permission. Click here to view.

VIDEO 2. Endoscopic endonasal approach for a nonsecreting pituitary adenoma and selective resection of the medial wall of the CS. Copyright Salomon Cohen-Cohen. Published with permission. Click here to view.

The mean preoperative serum GH level for patients with GH-secreting tumors was $14.9 \mu \mathrm{g} / \mathrm{L}$ (range 1.3-58.7 $\mu \mathrm{g} / \mathrm{L}$ ), and the average serum IGF-I level was $734 \mu \mathrm{g} / \mathrm{L}$ (range 333-1321 $\mu \mathrm{g} / \mathrm{L}$ ). The mean preoperative 24-hour UFC was $202 \mu \mathrm{g} / 24 \mathrm{hrs}$ (range $46-739 \mu \mathrm{g} / 24 \mathrm{hrs}$ ). The mean preoperative serum PRL level for patients with prolactinomas was $542.8 \mu \mathrm{g} / \mathrm{L}$ (range $30-1600 \mu \mathrm{g} / \mathrm{L}$ ).

\section{Follow-Up and Remission and Resection Rates}

Follow-up ranged from 4 to 64 months (mean 30 months, median 28 months) for patients with functional adenomas. For patients with nonfunctional adenomas, the follow-up ranged from 4 to 30 months (mean 16 months, median 20 months). Complete tumor resection, based on intraoperative impression and postoperative MRI, was achieved in all cases (Fig. 1). None of the patients with nonfunctional adenomas showed evidence of recurrence during this short follow-up period. Complete biochemical remission was initially achieved in all patients with functional adenomas (Fig. 2). One patient with a GH-secreting tumor who had initial remission at 3 months' follow-up had a recurrence within the 2 nd year. His preoperative levels of GH and IGF-I were $13.5 \mu \mathrm{g} / \mathrm{L}$ and $917 \mu \mathrm{g} / \mathrm{L}$, respectively. His postoperative IGF-I and GH levels at 3 
TABLE 1. Patient and tumor characteristics

\begin{tabular}{lcc}
\hline \multicolumn{1}{c}{ Characteristic } & No. of Cases & $\%$ \\
\hline Sex & & \\
\hline Female & 25 & 50 \\
\hline Male & 25 & 50 \\
\hline Tumor size & & \\
\hline Micro & 17 & 34 \\
\hline Macro & 33 & 66 \\
\hline Type of adenoma & & \\
\hline Nonfunctional & 15 & 30 \\
\hline Acromegaly & 16 & 32 \\
\hline Prolactinoma & 10 & 20 \\
\hline Cushing's & 9 & 18 \\
\hline Knosp grade & & \\
\hline 1 & 11 & 22 \\
\hline 2 & 23 & 46 \\
\hline 3 & 16 & 32 \\
\hline Ki-67 index & & \\
\hline$\leq 3$ & 44 & 88 \\
\hline$>3$ & 6 & 12 \\
\hline Medial wall invasion (histopathology) & 43 & 86 \\
\hline Previous surgery & 5 & 10 \\
\hline
\end{tabular}

months were 330 and $0.6 \mu \mathrm{g} / \mathrm{L}$, respectively. However, at 16 months and 36 months, his IGF-I levels increased to $430 \mu \mathrm{g} / \mathrm{L}$ and $534 \mu \mathrm{g} / \mathrm{L}$, respectively. This patient declined medical therapy (lanreotide) but underwent radiosurgery, and his last IGF-I level was within the normal range. At last follow-up, the initial remission rate in this short-term series of functional adenomas with medial wall invasion was $97 \%$ (34 of 35 cases). No adjuvant treatment was used for any patients, except for the patient with recurrence who underwent postoperative radiosurgery.

\section{Histopathology}

A total of 57 medial walls were removed in 50 patients. In 7 patients, bilateral wall involvement was suspected intraoperatively, and in those patients, bilateral resection of the medial wall was performed. Medial wall invasion was histologically confirmed in 43 of 50 patients (86\%) (Fig. 3) and in 14 of 15 nonfunctional adenomas (93\%) and 29 of 35 functional adenomas $(83 \%)$. Medial wall invasion was confirmed in $64 \%$ of patients with Knosp grade 1, $91 \%$ with Knosp grade 2, and 94\% with Knosp grade 3 disease. In the 7 cases in which bilateral medial wall removal was performed (3 cases of nonfunctional and 4 of functional adenoma), both medial walls were histologically positive for tumor. Medial wall invasion was confirmed in 11 patients $(65 \%)$ with microadenomas and 32 patients $(97 \%)$ with macroadenomas ( $\mathrm{p}<0.05)$. The Ki-67 index was $\leq 3$ in 44 cases $(88 \%)$ and $>3$ in only 6 cases $(12 \%)$.

\section{Complications}

There were no deaths or ICA injuries. The average blood loss was $378 \mathrm{ml}(50-1200 \mathrm{ml})$ with only 2 patients requiring a blood transfusion. One patient suffered a postoperative CSF leak (2\%) requiring reoperation for repair. Four patients $(8 \%)$ developed a new cranial nerve $(\mathrm{CN})$ palsy; 3 of them developed a partial CN VI palsy, immediately after surgery in 1 case and on postoperative day 1 in the other 2 cases. The first patient with an immediate onset of CN VI palsy had bilateral medial wall resection and developed a large clot (Fig. 4). This patient underwent early (within 24 hours of surgery) endonasal endoscopic re-exploration with clot evacuation and was found to have active bleeding from an inferior hypophyseal artery that had not been completely coagulated; this was one of the earliest cases in this series. The 2 cases of delayed (postoperative day 1) CN VI palsy were treated conservatively with short-term steroids as the palsy was found to be only mild on examination. In one of these cases, a small clot in the CS was visualized on the MR images obtained on postoperative day 1 (Fig. 5), while the other case was thought to be secondary to excessive CS packing, but with no structural cause visualized on MRI. The remaining patient developed a partial CN III palsy 1 week after surgery due to an excessively large fat graft placed in the sella and extending into the CS; the patient was taken back to surgery for fat graft removal. In all 4 cases, the cranial nerve palsies had completely resolved at 3 months' follow-up, resulting in no permanent neurological morbidity.

\section{Discussion}

In this study, we describe the surgical results of the endoscopic endonasal selective resection of the medial wall of the CS. These results demonstrate that this technique can be safely used with minimal morbidity and may improve rates of remission in patients with functional adenomas and medial wall invasion. This report is focused on the subset of tumors without extensive CS invasion, but rather with attachment or endoscopically identified, isolated medial wall invasion. This is evidenced by the lack of Knosp 4 tumors in the cohort.

One of the most important causes of surgical failure and high rates of recurrence in cases of functional adenoma is unrecognized dural invasion. Dickerman and Oldfield ${ }^{3}$ concluded that the medial wall of the CS is by far the most likely site for dural invasion to be detected. It has been noticed that dural invasion tends to be more common with larger tumors, $3,12,13,20,21$ and this is confirmed in our study. Different techniques to maximize the degree of resection and improve rates of remission in patients with invasive functional adenomas have been described. Lonser et al. ${ }^{12}$ reported the results of a prospective study of 87 patients with Cushing's disease. Medial wall resection (partial or complete) was performed in 18 patients with presumed invasion identified at surgery. Oldfield suggested that excision of the medial wall should only be attempted for patients in whom it is likely that a cure can be achieved, given the risk of this surgical procedure, ${ }^{17,18}$ and he recently provided a step-by-step description of his surgical technique. ${ }^{17}$ Nishioka et al. ${ }^{16}$ described their results in 150 patients with $\mathrm{GH}$-secreting adenomas and stated that the medial wall of the CS was sharply excised if an invasion was suspected. Histological examination showed invasion of the medial 

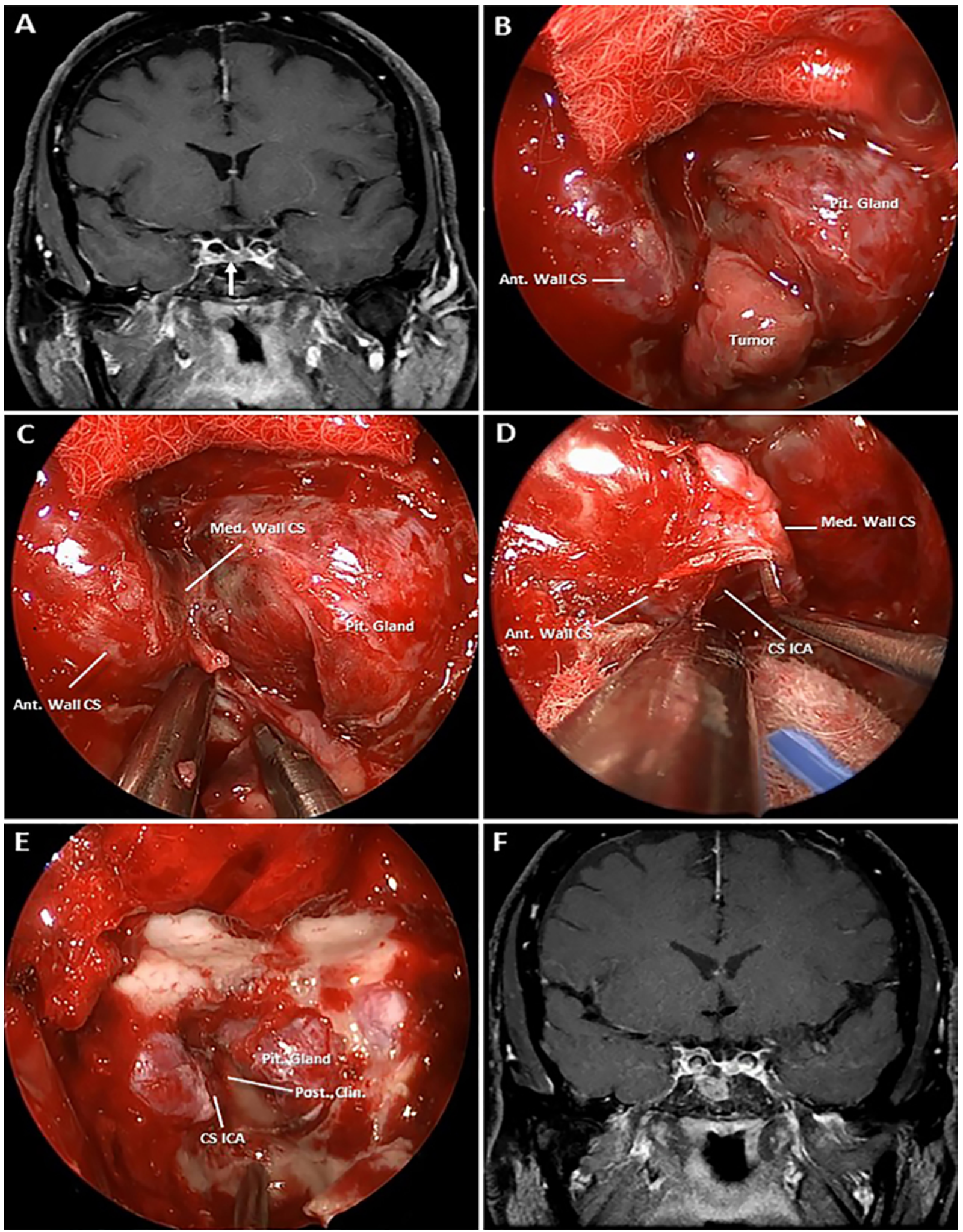

FIG. 1. Case involving a 69 -year-old patient with abnormal IGF levels $(1004 \mu \mathrm{g} / \mathrm{L})$ and acromegalic features. A: Preoperative coronal postcontrast T1-weighted MR image showing a pituitary microadenoma $(5 \mathrm{~mm}$, arrow) adjacent to the right medial CS wall. B: Intraoperative view of the tumor after extracapsular dissection. C: Identification of the area suspicious for tumor invasion at the inferior aspect of the medial wall of the CS. D: Separation between the medial and anterior walls of the CS and mobilization of the medial wall away from the ICA. E: The medial wall has been completely removed, with exposure of the cavernous ICA laterally and the posterior clinoid posteriorly. F: Postoperative coronal postcontrast T1-weighted MR image showing complete tumor and right medial wall resection. The patient had normal IGF levels and resolution of acromegalic symptoms at 3 months' follow-up. Ant. = anterior; Clin. = clinoid; Med. = medial; Pit. = pituitary; Post. = Posterior. Figure is available in color online only. 

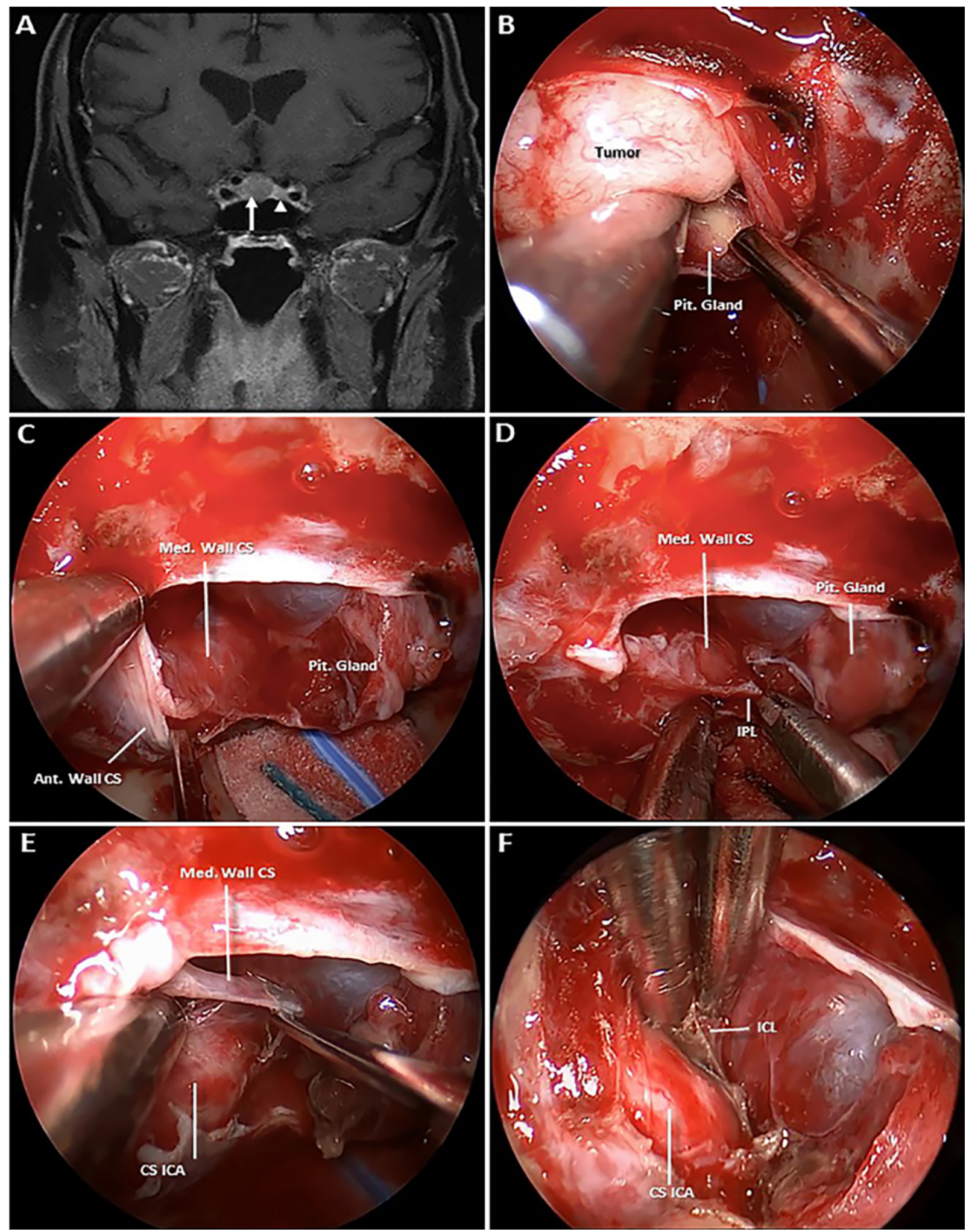

FIG. 2. Case involving a 44-year-old patient presenting with elevated UFC levels (734 $\mu \mathrm{g} / 24 \mathrm{hr}$ ) and symptoms of Cushing's disease. A: Preoperative coronal postcontrast T1-weighted MR image showing a hypoenhancing pituitary adenoma $(10 \mathrm{~mm}$, arrow) with potential right medial wall invasion and displacing the gland to the left (arrowhead). B: Intraoperative view of the tumor during extracapsular dissection. C: Opening of the anterior wall of the CS after tumor invasion of the medial wall was suspected. D: Transection of the inferior parasellar ligament, which is attached to the vertical portion of the cavernous ICA. E: Mobilization of the medial wall away from the ICA and progressing in a posterior direction. F: Intraoperative image with a $45^{\circ}$ scope showing the interclinoid ligament after complete right medial wall resection. Ant. = anterior; ICL = interclinoid ligament; $\mathrm{IPL}=$ inferior parasellar ligament; Med. = medial; Pit. = pituitary. Figure is available in color online only. 

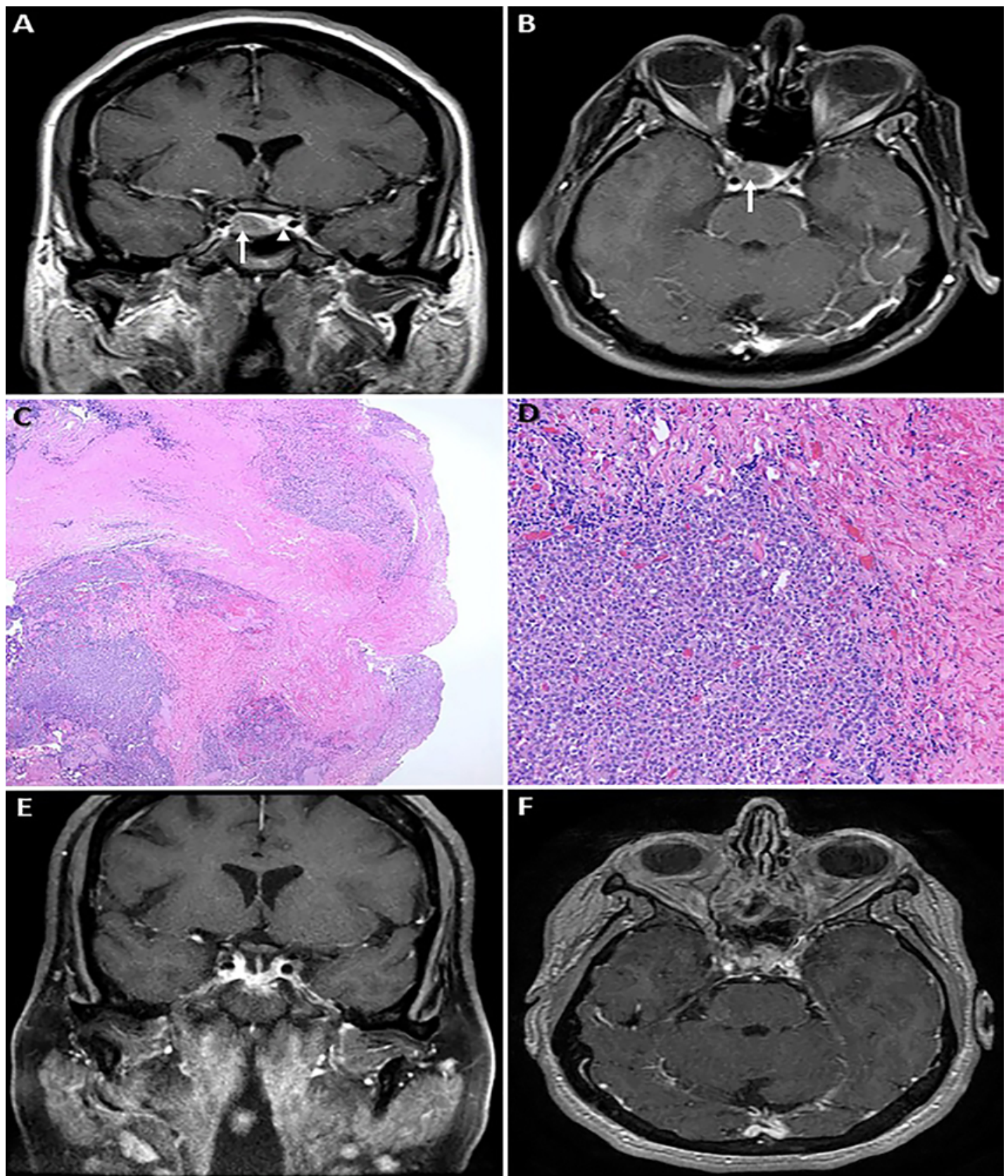

FIG. 3. MR images and histological findings obtained in a 41-year-old patient with a GH-secreting adenoma and evidence of right medial wall invasion during surgery and upon histological analysis. A and B: Preoperative coronal (A) and axial (B) postcontrast T1-weighted MR images showing a hypoenhancing pituitary adenoma (12 $\mathrm{mm}$, arrow) displacing the gland to the left (arrowhead). $\mathrm{C}$ and $\mathrm{D}$ : Photomicrographs of $\mathrm{H} \& \mathrm{E}$-stained sections of the right medial wall of the CS obtained during surgery demonstrating tumor invasion. E and F: Postoperative coronal $(E)$ and axial $(F)$ postcontrast T1-weighted MR images showing complete tumor resection. Figure is available in color online only.

wall in $16(88.9 \%)$ of 18 samples. Their technique is briefly described as a direct opening of the medial wall followed by sharp excision if invaded by tumor. Other authors, including Ceylan et al., ${ }^{2}$ Woodworth et al., ${ }^{27}$ and Kitano et al., ${ }^{9}$ have described different techniques to remove tumor from the CS but not techniques to specifically remove the medial wall when the CS is not frankly breached.

Micko et al. ${ }^{14}$ stated that direct visual inspection of the entire medial wall of the CS using endoscopes offers significant advantages over microscopic transsphenoidal surgery for detecting adenoma invasion. In their opinion, despite the endoscopic technique, a direct biopsy of the connective tissue of the medial CS wall seems to be too dangerous and is not feasible in routine clinical practice because of the danger of injuring neurovascular structures. Lonser et al. ${ }^{12}$ concluded that resection of the medial wall should only be performed by very experienced surgeons. Indeed, this is a critical point. All surgeries in 

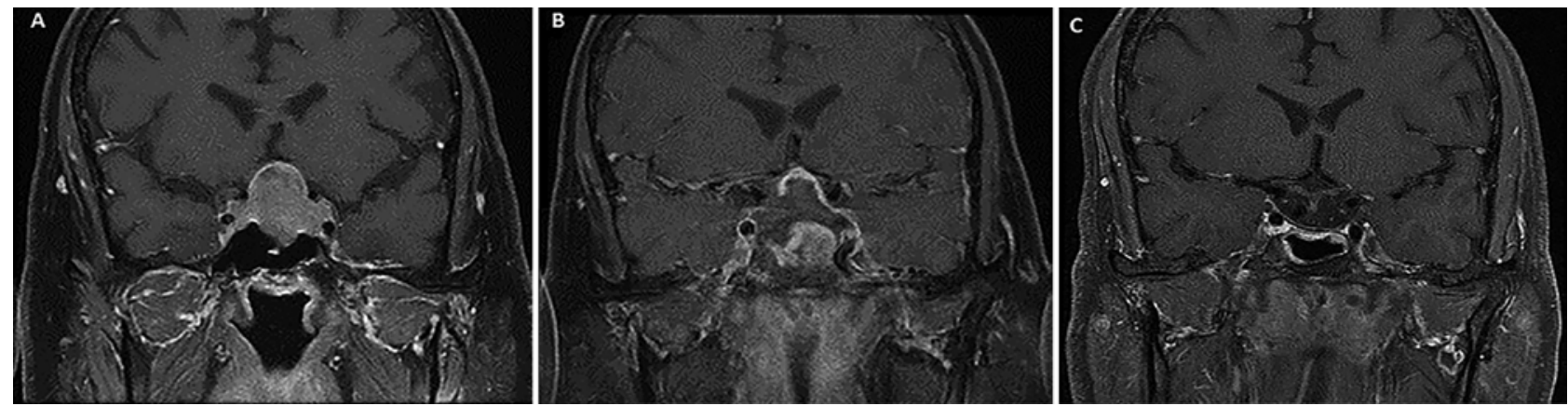

FIG. 4. Case involving a 33-year-old patient with Cushing's symptoms and abnormal UFC levels (317 $\mu \mathrm{g} / 24 \mathrm{hrs})$. A: Preoperative coronal postcontrast T1-weighted MR image showing a pituitary macroadenoma $(28 \mathrm{~mm})$ with potential bilateral medial wall invasion. B: Early postoperative coronal T1-weighted MR image obtained after the patient underwent removal of the medial wall of CS bilaterally and developed a progressive CN VI palsy. The MRI study showed complete tumor resection but presence of a largesize clot occupying the tumor bed, for which the patient subsequently underwent surgical evacuation. C: Postoperative coronal T1-weighted MR image obtained after surgical re-exploration and clot evacuation. Complete improvement of the CN VI palsy was achieved at 3 months' follow-up, and the patient remained in clinical and biochemical remission at 5 years' follow-up.

this study were performed by experienced endonasal skull base teams who regularly perform endonasal and open skull base surgery for both pituitary and nonpituitary tumors, including complex skull base lesions that often require endonasal transcavernous approaches, as previously described. ${ }^{4,5,10,11,24,26}$ In addition, the use of the 2-surgeon, 4-hand technique is critical for performing the delicate maneuvers required to safely resect the medial CS wall. The number of cases required for such surgery is not well established, but progressive levels of training have been proposed, with these cases considered as level V/V given the ICA dissection and management necessary. ${ }^{24}$ As such, it is critical that these results not be assumed to be reproducible without similar experience or techniques.

Oldfield first described the steps for the microscopic transsphenoidal "en bloc" removal of microadenoma with invasion of the medial wall of the CS. ${ }^{17}$ Here we further develop this technique for endoscopic endonasal selective medial wall removal by providing key anatomical landmarks and surgical steps and demonstrating its application in a large series of invasive adenomas. The surgical technique proposed here is based on the understanding of the anatomy of the medial wall and its ligaments, as described in part 1 of this study. ${ }^{25}$ By opening first the anterior wall of the CS, as described by Oldfield, we can achieve early control of the venous bleeding. This also allows early and accurate identification of the ligaments that anchor the medial wall to the cavernous ICA, selective coagulation of the inferior hypophyseal artery (IHA), and careful transection of the ligaments and the IHA to gradually detach and mobilize the medial wall away from the cavernous ICA. These surgical steps were not described by Oldfield, and they represent a novel surgical description. The proposed technique also provides anatomical landmarks, such as the caroticoclinoid ligament, the interclinoid ligament, the posterior clinoid, the posterior gland, and the sellar diaphragm, that facilitate the complete resection of the medial wall beyond the area of tumor invasion. Of note, this technique can be modified to provide some degree of preservation of the normal anatomy of the medial wall of the CS, tailoring the resection to each case.
It is important to notice that all the previously reported series on medial wall removal only included patients with functional tumors. The surgical technique we propose here was first used only in patients with functional tumors and intraoperative findings of medial wall invasion. Once the surgical technique proved safe and successful, we started using it selectively in patients with nonfunctional tumors that were clearly invading the medial wall. This is evidenced by the different mean follow-up lengths for nonfunctional (16 months) and functional adenomas (30 months). Remarkably, the histopathology was positive for medial wall invasion in $93 \%$ of the nonfunctional cases, which indicates that the selection process in this group of patients was very precise. It is critical to emphasize that resection of the medial wall of the CS for nonfunctional adenomas should not be recommended except for highly selected cases and very experienced surgeons. Residual adenomas are, most frequently, slow-growing tumors that can be watched or treated conservatively with stereotactic radiosurgery. Consequently, a safer strategy for many surgeons with less experience is not removing the medial wall and simply treating biochemical or radiological recurrences with stereotactic radiosurgery. In our practice, when there is evidence of medial wall invasion in nonfunctional adenomas, one safe and valid option is to gently but extensively coagulate the medial wall to shrink and eliminate any residual tumor.

This study demonstrates that with extensive surgical experience and proper surgical neuroanatomical knowledge, this technique can be successfully applied with low rates of associated complications. The risk of cranial nerve palsy is low because of the nerves' distant location relative to the medial wall, and the main cause for cranial nerve injury in our series was related to mass effect secondary to blood clot formation or excessive packing material in the CS. Venous bleeding from the CS can be cumbersome, and the risk of postoperative hematoma is unavoidable. Hemostasis maneuvers (intracavernous injection of Surgifoam [Ethicon, Inc.], irrigation, and gentle packing with cottonoids) should be repeated as many times as needed during the approach but should be done judiciously, avoiding excessive 

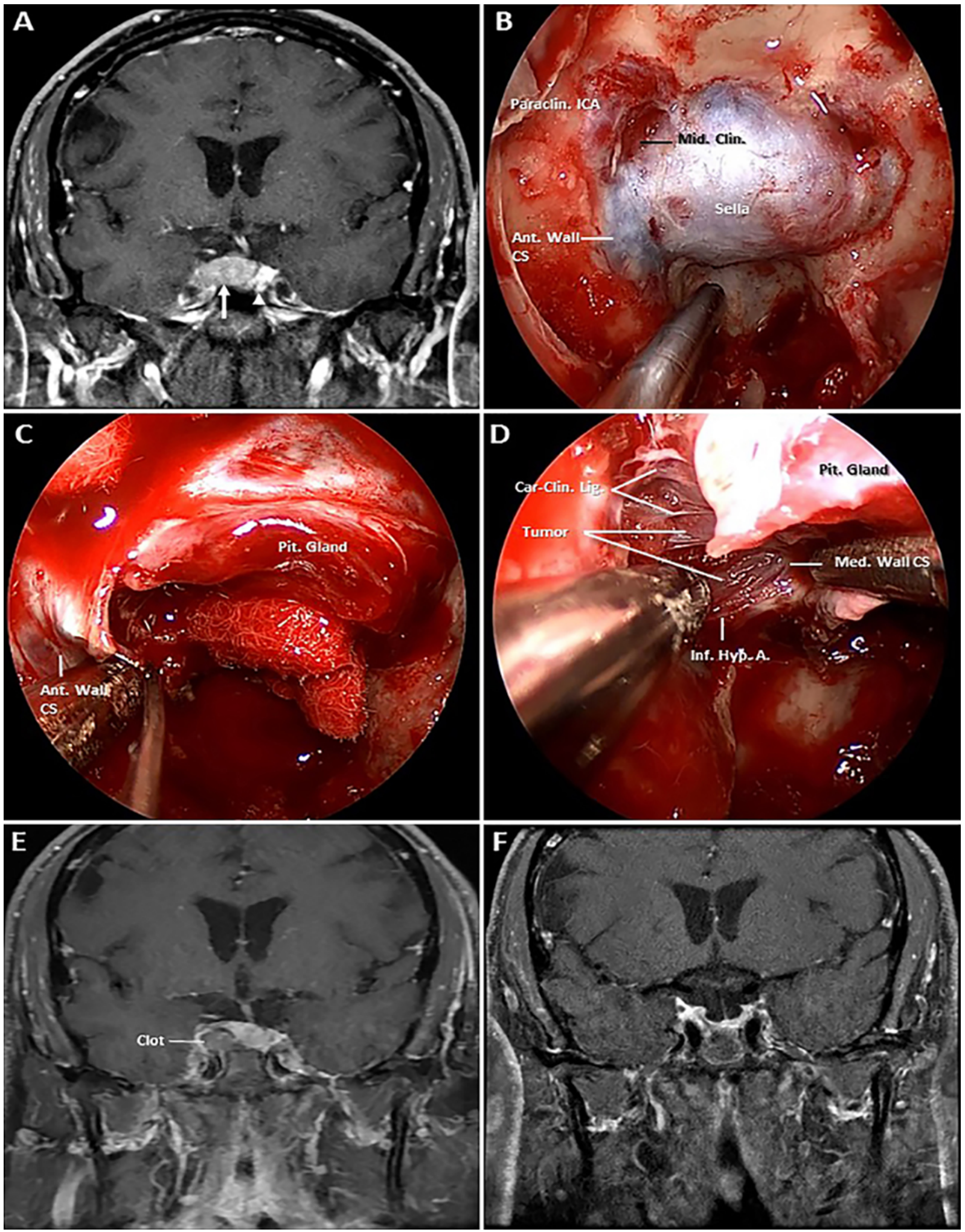

FIG. 5. Case involving a 64-year-old patient with secondary hypogonadism and a nonsecreting pituitary adenoma. A: Preoperative coronal postcontrast T1-weighted MR image showing an adenoma (arrow) with potential right medial wall invasion and displacing the gland to the left (arrowhead). B: Intraoperative image of the anterior wall of the CS and paraclinoid segment of the ICA after adequate sellar and parasellar exposure. C: Opening of the anterior wall of the CS was performed after evidence of invasion of the medial wall was observed intraoperatively. D: Selective coagulation and transection of the IHA to mobilize the medial wall of the CS away from the ICA; there is obvious tumor attached to the medial wall of the CS. FIG. 5. (continued) $\rightarrow$ 
FIG. 5. E: Postoperative coronal postcontrast T1-weighted MR image showing complete tumor and right medial wall resection with the presence of a small Surgicel-related blood clot in the CS. F: Three-month follow-up coronal postcontrast T1-weighted MR image obtained after conservative treatment with steroids showing complete resolution of the blood clot; the patient had complete recovery of the partial CN VI palsy just 2 weeks after surgery. Ant. = anterior; Car.-Clin. Lig. = caroticoclinoid ligament; Clin = clinoid; Inf. Hyp. A. = inferior hypophyseal artery; Paraclin. = paraclinoid; Pit. = pituitary; Med. = medial; Mid. = middle. Figure is available in color online only.

packing. All cases of cranial nerve palsy in our case series resolved completely with appropriate management. In general, if these patients develop a delayed palsy, it is typically due to swelling of hemostatic agents and can be observed. It is undeniable that the most important risk associated with this technique is ICA injury. To prevent this, we always use intraoperative Doppler probe and image guidance to identify the ICA trajectory. The use of right angle dissecting knives with a blunt tip (Mizuho "featherblade" or McElveen-Hitzelberger dissector) has been invaluable, as it allows the surgeon to first dissect over the ICA with a blunt instrument and only cut after the plane has been safely dissected under direct visualization. The surgeon must study the configuration of the cavernous ICA very carefully, both pre- and intraoperatively, as it is highly variable and potentially tortuous, particularly, but not exclusively, in patients with acromegaly. To avoid the risk of postoperative hematoma, as it happened early on this series, and the risk of arterial avulsion, we recommend selective coagulation and transection of the IHA. While not technically easy, this avoids complications and entails minimal risk to pituitary function, as recently demonstrated. ${ }^{4}$

\section{Limitations of the Study}

This study suffers from the limitations of a retrospective study. We believe that this technique will likely reduce the recurrence of tumors, but its recent implementation results in a relatively short follow-up, and we cannot provide long-term results. It will be important to define which patients are ideally suited for this procedure, provide longer follow-up to ensure lasting remission/cure, and determine whether the additional risk changes the outcome (particularly for null cell tumors). The relatively small number of patients is another important limitation of the present study. Also, there is an inherent selection bias for tumors with isolated but resectable medial CS wall invasion. The primary limitations of the proposed technique include the need for a long learning curve for anatomical understanding, team surgery, and surgical technique.

\section{Conclusions}

In select cases with isolated invasion of the medial wall of the CS, this structure can be removed safely and effectively, with minimal morbidity and excellent resection and remission rates. Further follow-up is needed to determine the long-term results of this technique. This technique requires team surgery and can only be applied after the surgical team has had significant experience.

\section{References}

1. Almeida JP, Ruiz-Treviño AS, Liang B, Omay SB, Shetty SR, Chen YN, et al: Reoperation for growth hormone-secreting pituitary adenomas: report on an endonasal endoscopic series with a systematic review and meta-analysis of the literature. J Neurosurg [epub ahead of print September 1, 2017. DOI: 10.3171/2017.2.JNS162673]

2. Ceylan S, Koc K, Anik I: Endoscopic endonasal transsphenoidal approach for pituitary adenomas invading the cavernous sinus. J Neurosurg 112:99-107, 2010

3. Dickerman RD, Oldfield EH: Basis of persistent and recurrent Cushing disease: an analysis of findings at repeated pituitary surgery. J Neurosurg 97:1343-1349, 2002

4. Fernandez-Miranda JC, Gardner PA, Rastelli MM Jr, PerisCelda M, Koutourousiou M, Peace D, et al: Endoscopic endonasal transcavernous posterior clinoidectomy with interdural pituitary transposition. J Neurosurg 121:91-99, 2014

5. Fernandez-Miranda JC, Zwagerman NT, Abhinav K, Lieber S, Wang EW, Snyderman CH, et al: Cavernous sinus compartments from the endoscopic endonasal approach: anatomical considerations and surgical relevance to adenoma surgery. J Neurosurg [epub ahead of print September 1, 2017. DOI: 10.3171/2017.2.JNS162214]

6. Giustina A, Chanson P, Bronstein MD, Klibanski A, Lamberts $\mathrm{S}$, Casanueva FF, et al: A consensus on criteria for cure of acromegaly. J Clin Endocrinol Metab 95:3141-3148, 2010

7. Hofstetter CP, Shin BJ, Mubita L, Huang C, Anand VK, Boockvar JA, et al: Endoscopic endonasal transsphenoidal surgery for functional pituitary adenomas. Neurosurg Focus 30(4):E10, 2011

8. Jane JA Jr, Starke RM, Elzoghby MA, Reames DL, Payne SC, Thorner MO, et al: Endoscopic transsphenoidal surgery for acromegaly: remission using modern criteria, complications, and predictors of outcome. J Clin Endocrinol Metab 96:2732-2740, 2011

9. Kitano M, Taneda M, Shimono T, Nakao Y: Extended transsphenoidal approach for surgical management of pituitary adenomas invading the cavernous sinus. J Neurosurg 108:26-36, 2008

10. Koutourousiou M, Gardner PA, Tormenti MJ, Henry SL, Stefko ST, Kassam AB, et al: Endoscopic endonasal approach for resection of cranial base chordomas: outcomes and learning curve. Neurosurgery 71:614-625, 2012

11. Koutourousiou M, Vaz Guimaraes Filho F, Fernandez-Miranda JC, Wang EW, Stefko ST, Snyderman CH, et al: Endoscopic endonasal surgery for tumors of the cavernous sinus: a series of 234 patients. World Neurosurg 103:713-732, 2017

12. Lonser RR, Ksendzovsky A, Wind JJ, Vortmeyer AO, Oldfield EH: Prospective evaluation of the characteristics and incidence of adenoma-associated dural invasion in Cushing disease. J Neurosurg 116:272-279, 2012

13. Meij BP, Lopes MBS, Ellegala DB, Alden TD, Laws ER Jr: The long-term significance of microscopic dural invasion in 354 patients with pituitary adenomas treated with transsphenoidal surgery. J Neurosurg 96:195-208, 2002

14. Micko AS, Wöhrer A, Wolfsberger S, Knosp E: Invasion of the cavernous sinus space in pituitary adenomas: endoscopic verification and its correlation with an MRI-based classification. J Neurosurg 122:803-811, 2015

15. Nieman LK, Biller BMK, Findling JW, Murad MH, NewellPrice J, Savage MO, et al: Treatment of Cushing's syndrome: an Endocrine Society clinical practice guideline. J Clin Endocrinol Metab 100:2807-2831, 2015

16. Nishioka H, Fukuhara N, Horiguchi K, Yamada S: Aggres- 
sive transsphenoidal resection of tumors invading the cavernous sinus in patients with acromegaly: predictive factors, strategies, and outcomes. J Neurosurg 121:505-510, 2014

17. Oldfield EH: Cushing's disease: lessons learned from 1500 cases. Neurosurgery 64 (CN Suppl 1):27-36, 2017

18. Oldfield EH: Editorial. Management of invasion by pituitary adenomas. J Neurosurg 121:501-503, 2014

19. Paluzzi A, Fernandez-Miranda JC, Tonya Stefko S, Challinor S, Snyderman CH, Gardner PA: Endoscopic endonasal approach for pituitary adenomas: a series of 555 patients. Pituitary 17:307-319, 2014

20. Scheithauer BW, Kovacs KT, Laws ER Jr, Randall RV: Pathology of invasive pituitary tumors with special reference to functional classification. J Neurosurg 65:733-744, 1986

21. Selman WR, Laws ER Jr, Scheithauer BW, Carpenter SM: The occurrence of dural invasion in pituitary adenomas. J Neurosurg 64:402-407, 1986

22. Shin SS, Gardner PA, Ng J, Faraji AH, Agarwal N, Chivukula S, et al: Endoscopic endonasal approach for adrenocorticotropic hormone-secreting pituitary adenomas: outcomes and analysis of remission rates and tumor biochemical activity with respect to tumor invasiveness. World Neurosurg 102:651-658, 658.e1, 2017

23. Shin SS, Tormenti MJ, Paluzzi A, Rothfus WE, Chang YF, Zainah H, et al: Endoscopic endonasal approach for growth hormone secreting pituitary adenomas: outcomes in 53 patients using 2010 consensus criteria for remission. Pituitary 16:435-444, 2013

24. Snyderman C, Kassam A, Carrau R, Mintz A, Gardner P, Prevedello DM: Acquisition of surgical skills for endonasal skull base surgery: a training program. Laryngoscope 117:699-705, 2007

25. Truong HQ, Lieber S, Najera E, Alves-Belo JT, Gardener PA, Fernandez-Miranda JC: The medial wall of the cavernous sinus. Part 1: Surgical anatomy, ligaments, and surgical technique for its mobilization and/or resection. $\mathbf{J}$ Neurosurg [epub ahead of print September 7, 2018. DOI: 10.3171/2018.3.JNS18596]

26. Vaz-Guimaraes F, Fernandez-Miranda JC, Koutourousiou M, Hamilton RL, Wang EW, Snyderman CH, et al: endoscopic endonasal surgery for cranial base chondrosarcomas. Oper Neurosurg (Hagerstown) 13:421-434, 2017

27. Woodworth GF, Patel KS, Shin B, Burkhardt JK, Tsiouris AJ, McCoul ED, et al: Surgical outcomes using a medial-tolateral endonasal endoscopic approach to pituitary adenomas invading the cavernous sinus. J Neurosurg 120:1086-1094, 2014
28. Zoli M, Milanese L, Bonfatti R, Sturiale C, Pasquini E, Frank G, et al: Cavernous sinus invasion by pituitary adenomas: role of endoscopic endonasal surgery. J Neurosurg Sci 60:485-494, 2016

\section{Disclosures}

The authors report no conflict of interest concerning the materials or methods used in this study or the findings specified in this paper.

\section{Author Contributions}

Conception and design: Fernandez-Miranda, Gardner. Acquisition of data: Cohen-Cohen, Alves-Belo, Truong. Analysis and interpretation of data: Fernandez-Miranda, Cohen-Cohen, Gardner, Alves-Belo, Truong. Drafting the article: Fernandez-Miranda, Cohen-Cohen. Critically revising the article: Fernandez-Miranda, Cohen-Cohen, Gardner, Snyderman, Wang. Reviewed submitted version of manuscript: Fernandez-Miranda, Cohen-Cohen, Gardner, Snyderman, Wang. Approved the final version of the manuscript on behalf of all authors: Fernandez-Miranda. Statistical analysis: Cohen-Cohen. Administrative/technical/ material support: Cohen-Cohen. Study supervision: FernandezMiranda, Gardner.

\section{Supplemental Information \\ Videos \\ Video 1. https://vimeo.com/269005424. \\ Video 2. https://vimeo.com/269005366.}

\section{Companion Papers}

Truong HQ, Lieber S, Najera E, Alves-Belo JT, Gardner PA, Fernandez-Miranda JC: The medial wall of the cavernous sinus. Part 1: Surgical anatomy, ligaments, and surgical technique for its mobilization and/or resection. DOI: 10.3171/2018.3.JNS18596.

\section{Previous Presentations}

Portions of this work were presented in abstract form at the NASBS 28th annual meeting in San Diego, California, February 17, 2018.

\section{Correspondence}

Juan C. Fernandez-Miranda: Department of Neurological Surgery, Stanford University, Stanford, CA.drjfm@stanford.edu. 